\title{
A RFID-based JIT Application for Least Waiting Time for Dynamic Smart Diet Customers
}

\author{
Long-Fei CHEN ${ }^{\mathrm{a}}$ and Shu-Jun CHEN \\ ${ }^{1}$ Department of Management Engineering, Business College, NanFang College of Sun Yat-Sen University, \\ GuangZhou, China, 510970
}

\begin{abstract}
Waiting in queue is part of everyone's life. A day may include several different waiting in queue. Waiting in line is always a bit of phenomena for a prosperous restaurant at dinner time. How to manage the queues and keep their feet into customers is the operating challenge facing everyone manager. In addition, rising energy costs and growing demand for protection of the environment call for a shorter waiting queue. Thus, we devise a dynamic smart diet App manager to reduce customer waiting time through radio frequency identification (RFID) and just in time (JIT) principle to reduce inventory of restaurant food materials, thereby increasing customer satisfaction and loyalty, and improving revenue and social responsibility.
\end{abstract}

\section{Introduction}

How to manage the waiting queues and keep customers feet is the operating challenge facing everyone manager. A devised dynamic smart diet app manager can reduce customer waiting time and inventory of restaurant food materials, thereby increasing customer satisfaction and loyalty, and improving revenue and social responsibility[1].

Dynamic smart diet serves for customers who have ever come to the restaurant and have its membership cards. When customers arrived at the parking lots of the restaurant, their membership cards will be recognized by the RFID and then the recipe of the restaurant will be sent to the customer's cellphone automatically by the system[3,4]. What's more, some dishes will also be recommended by the system according to the customer's consumed menu. All of these can spend less time than sitting in the chair or waiting in queue to order.

Besides the use of RFID, JIT production is also adopted in the dynamic smart diet whose aim is to achieve zero-inventory or reduce inventory. The reason why JIT production, which comes from logistics management, can be introduced to catering services is that it's too difficult to predict each day's ingredients. All the ingredients are purchased in the morning, but not all of them in the menu are included. If what customer-needs are in shortage, the restaurant will recommend other dishes instead of restocking.

\footnotetext{
${ }^{a}$ Corresponding author: y2kmorg@yahoo.com
} 


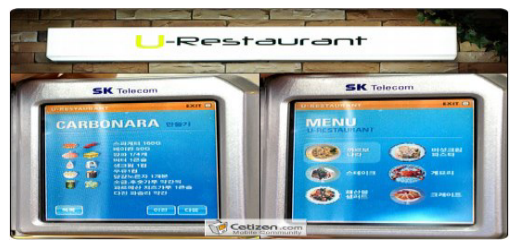

Figure 1. Smart diet recipe (Source : Microsoft Word)

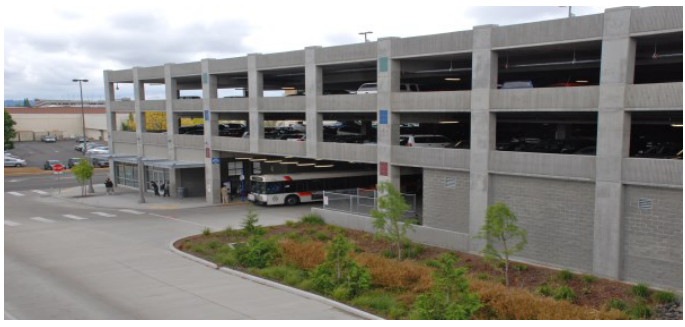

Figure 2. Smart diet recipe can be forwarded at parking yard after sensing RFID card (Source : Microsoft Word)

\section{Literature review}

As waiting lines have been associated with reduced service evaluations, negative perception of service quality, and reduced satisfaction, having to wait makes a customer's first experience of a service a negative one[1]. So, effectively manage queues is important.

In coming chaotic future of wearable electronics, devices can promise to connect real to digital lives seamlessly. These gadgets are rapidly multiplying, and within five years there could be half a billion devices strapped onto, or even embedded in, human bodies [2]. Internet of things (IOT) are constantly developing; the impact on traffic, medical, military has greatly increased. In this paper, we want to introduce IOT into the restaurant, which through RFID and app. RFID is a technology that has attracted considerable attention in the realm of information systems during recent years[3]. Thus, RFID technology is more widely accepted. Digitization, networking and information are the era characteristics of the 21 st century. With the rapid increasing number of mobile users, e-commerce has been in worldwide popularity and development. It provides the world with a good environment of trades and greatly facilitates the communication, saves the costs of management as well as the enterprise costs[4]. With the popularity of mobile phones, various apps also came into being, which brings opportunities for our vision of smart recipes.

There is an excessive consumption which may lead to 7 trends of crises, including destruction of the atmosphere, energy crisis, social decline and conflicts and so on $[5,8]$. Now climate change is really great, global warming is getting worse. As part of the planet citizenship is the responsibility of hours from his side to start. If restaurant can control their food storage by JIT principle, it can reduce waste of perish food due to over duration time. In fact, it can save raw materials down from dining with less waste and protect our environment.

Security is always a problem for wireless networks. Although encryption is becoming more pervasive and advanced, it is not always fully used in low-cost wearable devices. California-based information-management company Symantec revealed that the location of many health monitors can be easily tracked. And some of their passwords are vulnerable to hacking in clear text in wireless communication. Either because of unnecessarily broad permissions or because of malware, the smartphone or hub device that links it to the Internet could also be a weak point, even if a health monitor is encrypted[2].

As the coming advance of new wireless sensor networks, restaurants can adopt new technology like references to enhance their app recipe with ZigBee-based RFID system in a longer distance 
before their customers reach their parking yard [6,7]. If the smart diet recipe can integrated with werable devices, it may suggest suitable recepie to fit customers' current physical health after comparing the status of pressure, heartbeat rate and sleep hours[9].

\section{Research method}

\subsection{Methodology}

Firstly, some terminologies related to our method will be introduced.

JIT production is the production pattern of producing something in time as well as on time based on the demand. Its aim is to accelerate the circulation of semi-manufactured products, which can minimize the overstocked products and then enhance the production efficiency of enterprises.

RFID (Radio Frequency Identification) technology is a communication technology, which can identify specific targets and then record some related data without the help of the identification of the mechanical and optical contacts between the system and specific targets.

MRP (Material Requirement Planning) is a system designed to be used in information processing of inventory management in manufacturing. It solves the problem of the inventory management towards manufacturing, especially about how to get the needed products on time.

Green Logistics (Environmental logistics) is to stop the environment from being destroyed during the process of logistic, which can help to achieve the goal of purifying the logistic environment and make the best of logistics resources. It includes the whole greening process of logistics operation and management. Logistics operation consists of green transportation, green packaging, and green circulating processing and so on. As for the logistics management, it gives priority to the environmental protection and resource saving to improve logistics system. It is necessary to consider the positive aspects of green logistics. The ultimate goal is the sustainable development of green logistics, whose criterion is the unification of economic interests, social interests and environmental interests.

\subsection{Design features}

The dynamic smart diet is considered to make the use of JIT production, RFID, materials management and some other knowledge from the major of logistics management. The idea may have the following three advantages :

Saving customers' time is the most basic advantage of all. What dynamic smart diet wants to achieve is saving customer's waiting time, which can help them to have enough time to enjoy their food, take a break after their busy work, listen to some music, think about life and so on, which help a lot in their physical and spiritual health. For restaurants, more customers will be attracted because of the less waiting time and their satisfaction and loyalty towards restaurants will be enhanced.

Secondly, it can increase profits of restaurants. To apply RFID to hotels or restaurants can combine logistics management with hotel management: customers will receive membership cards with electronic tags after their first consumption, and when they come to the restaurant again, their cards will be recognized by the reader when they arrived at the parking lots of the restaurant. Although it costs much on RFID, the advanced satisfaction and loyalty of customers will make big profits. With RFID technology, customers' waiting time are less than before and more customers can be received in given time.

Finally, it follows the principle of green logistics. Green Logistics aims to achieve environmental protection and resource conservation. To apply dynamic smart diet to restaurants, restaurants can check the adequacy of the ingredients they need according to the customers' orders, if not; they'll give a feedback to the customer and recommend other dishes for them through the system. There are two advantages from doing these: one is cost saving from restocking; the other is the reduction of the 
restaurant's inventory. The goal of JIT is just the reduction of inventory, which can reduce waste and ensure the quality of ingredients, especially fruit and vegetables.

\subsection{Questionnaire}

Questionnaire is the most widely used method for data collection, which is feasible and effective. It is economical and timesaving. In order to testify the hypothesis effectively, the study will base on the general principles and methods of empirical research, using questionnaires to testify the theoretical construction [8]. This paper is the use of questionnaires, they were investigating RFID and smart approach to customer recipes, restaurant managers.

There is a questionnaire is for customers, researching for their frequency and reasons of dining out and their attitudes towards membership cards with RFID.

\subsection{Hypotheses and t-test}

Observation will also be adopted during the research because of the subjectivity and limitations of questionnaires. It will be used to verify hypotheses with t-test.

\section{Results}

The questionnaire is used for data collection in the the study, but because of the limited time and capability, only 152 of them have responses. Table 1 shows the listed primary results.

\subsection{Sample description}

Table 1. Personal Information of Sample 1

\begin{tabular}{|c|c|c|c|c|}
\hline Variable & Sort & Frequency & Percent (\%) & $\begin{array}{l}\text { Cumulative } \\
\text { Percent }(\%)\end{array}$ \\
\hline \multirow{2}{*}{ Gender } & Male & 67 & 44.08 & 44.08 \\
\hline & Female & 85 & 55.92 & 100 \\
\hline \multirow{5}{*}{ Age } & Under 20 & 2 & 1.32 & 1.32 \\
\hline & $20-29$ & 70 & 46.05 & 47.37 \\
\hline & $30-39$ & 50 & 32.89 & 80.26 \\
\hline & $40-49$ & 27 & 17.76 & 98.02 \\
\hline & Above 50 & 3 & 1.97 & 100 \\
\hline \multirow{5}{*}{ Occupation } & Student & 68 & 44.74 & 44.74 \\
\hline & Office worker & 50 & 32.89 & 77.63 \\
\hline & $\begin{array}{c}\text { Private business } \\
\text { employer }\end{array}$ & 18 & 11.84 & 89.47 \\
\hline & Free profession & 11 & 7.24 & 96.71 \\
\hline & Others & 5 & 3.29 & 100 \\
\hline
\end{tabular}

There are 67 males ( $44.08 \%$ of all) and 85 females (55.92\% of all) in the sample whose age ranges mainly from 20 to 29 years old while participants in 30-39 years old are in the second place. And most of them are students or office workers.

As for the education background, $30 \%$ of the participants have college degree and $40 \%$ of all have undergraduate degree. $85 \%$ of the participants have used smart-phones for more than 3 years. $75 \%$ of the participants dine out for more than fifth a month. Among those who dine out, $32.9 \%$ of them are office workers without time to cook while $50 \%$ of them dine out for parties of social activities. $86.27 \%$ of participants said that there are many customers in the restaurants where there have their meals. And $88.4 \%$ of all the participants have ever been in the trouble that they still had to wait for long time even though they had ordered. From the above information, it can be easily concluded that 
most of the participants are highly educated, and maybe it's easier for them to be open to trying new things. And the popularity of smart-phones makes the idea of using RFID possible. Faced with the problem of long waiting time in the restaurants, customers may be highly desired to use RFID and JIT technology to reduce their waiting time.

In the survey, $92.16 \%$ of the people are willing to use the following membership cards with RFID identification; $82.35 \%$ of people are willing to order a meal by app remotely, and have it after parking their car and reach the restaurant immediately; there are $74.51 \%$ of people are willing to pay for online ordering remotely.

Table 1. Key surveyed items with formatted responses

\begin{tabular}{|c|c|c|c|}
\hline & $\begin{array}{c}\text { App functions in } \\
\text { survey }\end{array}$ & Response & $\begin{array}{c}\text { Percentage } \\
(\%)\end{array}$ \\
\hline 1 & $\begin{array}{c}\text { willing to own } \\
\text { membership cards } \\
\text { with RFID }\end{array}$ & 140 & 92.16 \\
\hline 2 & $\begin{array}{c}\text { willing to order a } \\
\text { meal by app }\end{array}$ & 125 & 82.35 \\
\hline 3 & $\begin{array}{c}\text { willing to pay for } \\
\text { online ordering }\end{array}$ & 113 & 74.51 \\
\hline
\end{tabular}

\subsection{Hypotheses and t-test}

Let $\mathrm{U}_{1}$-the duration time of customers waiting time for the queue who do not use RFID, and

$\mathrm{U}_{2}$ - the duration time of customers waiting time for the queue who use RFID

Hypothesis $\mathrm{H}_{0}: \mathrm{U}_{1}=\mathrm{U}_{2}$

Hypothesis $\mathrm{H}_{1}: \mathrm{U}_{1}>\mathrm{U}_{2}$

T-test formula of statistics is used to analyze these two data sets in the EXCEL, and the result is that $\mathrm{P}$ value is very close to zero, which means that after the use of RFID, the time spent on waiting for the queue is remarkably reduced. It means $\mathrm{U}_{1}>\mathrm{U}_{2}$. Thus $\mathrm{H}_{0}$ is rejected, and $\mathrm{H}_{1}$ is accepted.

\subsection{Limitations}

Because of the limited time and incapability, available questionnaires that were returned are not enough to exactly represent all customers' opinions.

Besides, the recorded average duration time 100 sets of customers spending on waiting for the queue is around 11 minutes with the normal distribution, and it has a standard deviation of 3.8. From the data of simulated experiment, after the use of RFID, time can be reduced from 11 minutes to5.5 minutes with a normal distribution and a standard deviation of 1.7. And using t-test to analyze these two data sets in the EXCEL, and the result shows that $\mathrm{P}$ value is very close to zero, which means that after the use of RFID, the time spent on waiting for the queue is remarkably reduced. If there exists membership cards with RFID for coming into use, the results will be more persuasive.

The cost of RFID is a little too high for restaurants to apply it to their service. If the cost can be analyzed to work out the time when they can recover the cost or make profits, restaurants will be more eager to use it.

\section{Conclusions}

With the popularity of smart phones, various apps have emerged, but RFID technology has become increasingly mature, dynamic and intelligent recipe we want to conceive can be combined with RFID, JIT and MRP, to have three major advantages: the first reducing customer waiting time, and secondly, increase revenue, and more importantly, in favor of green logistics. We designed a questionnaire to 
the customer and the result shows most customers are willing to use this dynamic management of intelligent recipe. The simulation experiments have come to use RFID can significantly decrease the waiting time for dynamic smart diet customers with RFID. In real practice, security for customers' data needs to pay attention for special care.

\section{References}

1. Alinda Kokkinoua, David A. Cranageb, Using self-service technology to reduce customer waiting times, International Journal of Hospitality Management 33, 435-445. (2013)

2. KAT AUSTEN, the Trouble with Wearables, September, VOL 525, Nature, 23-24. (2015)

3. Henning Baars, Daniel Gille and Jens Stru"ker, Evaluation of RFID applications for logistics: a framework for identifying, forecasting and assessing benefits, European Journal of Information Systems, 18, 578-591. (2009)

4. Peng Gegang, Song Zhixing, Feng Zhanbo, Xiang Lisheng, Shen Jing, Li Renfa, Mobile client application for mobile electronic commerce research, The 2015 International Conference on Electronic Business, HongKong, December 6-10, (2015).

5. LongFei Chen, Book Review: The Little Green Handbook: Seven Trends Shaping the Future of Our Planet, Ron Nielsen, St. Martin's Press, New York, USA, ISBN 0-312-42581-3, Ecological Economics, 89, 202-203. (2013)

6. Cho, H., Kim, J., Baek, Y. Large-scale active RFID system utilizing ZigBee networks, IEEE Transactions on Consumer Electronics, 57 (2), 379-385. (2011)

7. Nellore, K.; Hancke, G.P., A Survey on Urban Traffic Management System Using Wireless Sensor Networks, Sensors, 16, 157. (2016)

8. Si-Ting Lee, Long-Fei Chen, Hui-Guo Zhu, A New Innovative IOT Watch Reduces Excessive Consumption and Its Implications to Green Logistics, The 2015 International Conference on Electronic Business, HongKong, December 6-10, (2015).

9. Kenry, Yeo, J. C., \& Lim, C. T. Emerging flexible and wearable physical sensing platforms for healthcare and biomedical applications, Microsystems \& Nanoengineering, 2, 16043, (2016). 